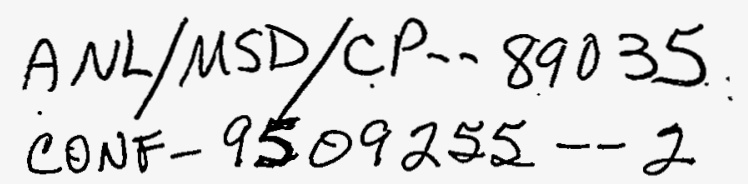

\title{
Structural Features that Optimize High Temperature Superconductivity
}

\author{
J. D. Jorgensen 1 , D. G. Hinks ${ }^{1}$, O. Chmaissem 1 , D. N. Argyriou', \\ J. F. Mitchell, and B. Dabrowski ${ }^{2}$ \\ ${ }_{1}$ Materials Science Division and Science and Technology Center for Superconductivity \\ Argonne National Laboratory \\ Argonne, IL 60439 \\ 2Physics Department \\ Northern Illinois University \\ DeKalb, IL 60115 \\ The submitted manuscript has beon avthored by a \\ contractor of the U.S. Government under contract No. W \\ 31-109-ENG-38. Accordingly, the U.S. Government \\ retains a nonexclusive, royalty free license to publish or \\ reproduce the published form of this contribution, or allow
others to do so, tor U.S. Government purposos.

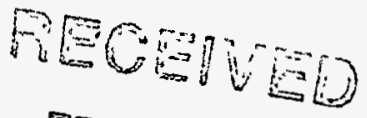

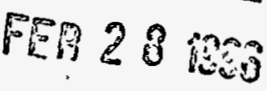

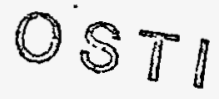 \\ January, 1996 \\ Invited paper for the First Polish-US Conference on High \\ Temperature Superconductivity, 11-15 September 1995, Wroclaw- \\ Duszniki ZDR., Poland. Proceeds to be published by Springer- \\ Verlag as a volume in their series "Lecture Notes in Physics.".
}

$/ \mathrm{sm}$

Distribution:

DISCLAIMER

$\begin{aligned} \text { 1-2. } & \text { M. J. Masek } \\ \text { 3. } & \text { B. D. Dunlap } \\ \text { 4. } & \text { G. W. Crabtree } \\ \text { 5. } & \text { J. D. Jorgensen } \\ \text { 6. } & \text { F. Y. Fradin } \\ \text { 7. } & \text { B. S. Brown } \\ \text { 8. } & \text { M. B. Brodsky } \\ \text { 9. } & \text { Editorial Office } \\ \text { 10. } & \text { Authors } \\ \text { 11. } & \text { S\&TC (5) }\end{aligned}$

This report was prepared as an account of work sponsored by an agency of the United States Government. Neither the United States Government nor any agency thereof, nor any of their employees, makes any warranty, express or implied, or assumes any legal liability or responsibility for the accuracy, completeness, or usefulness of any information, apparatus, product, or process disclosed, or represents that its use would not infringe privately owned rights. Reference herein to any specific commercial product, process, or service by trade name, trademark, manufacturer, or otherwise does not necessarily constitute or imply its endorsement, recom. mendation, or favoring by the United States Government or any agency thereof. The views and opinions of authors expressed herein do not necessarily state or reflect those of the United States Government or any agency thereof.

This work was supported by the Division of Materials Sciences, Office of Basic Energy Sciences of DOE, under contract No. W-31-109-ENG-38 (JDJ, DGH), the National Science Foundation, Office of Science and Technology Centers, under grant No. DMR 91-20000 (OC, DNA, BD), and the U. S. Department of Energy Distinguished Postdoctoral Research Program (JFM). 


\title{
Structural Features that Optimize High Temperature Superconductivity
}

\author{
J. D. Jorgensen 1 , D. G. Hinks ${ }^{1}$, O. Chmaissem 1 , D. N. Argyriou ${ }^{1}$, \\ J. F. Mitchell, and B. Dabrowski ${ }^{2}$ \\ $1_{\text {Materials Science Division and Science and Technology Center for Superconductivity }}$ \\ Argonne National Laboratory \\ Argonne, IL 60439 \\ 2Physics Department \\ Northern Illinois University \\ DeKalb, IL 60115

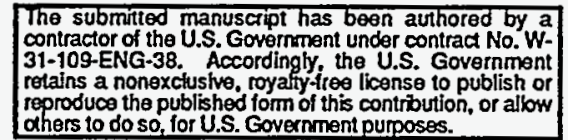 \\ reproduce the published form of this contribution, or allow

\section{January, 1996} \\ Invited paper for the First Polish-US Conference on High \\ Temperature Superconductivity, 11-15 September 1995, Wroclaw- \\ Duszniki ZDR., Poland. Proceeds to be published by Springer- \\ Verlag as a volume in their series "Lecture Notes in Physics."
}

/sm

This work was supported by the Division of Materials Sciences, Office of Basic Energy Sciences of DOE, under contract No. W-31-109-ENG-38 (JDJ, DGH), the National Science Foundation, Office of Science and Technology Centers, under grant No. DMR 91-20000 (OC, DNA, BD), and the U. S. Department of Energy Distinguished Postdoctoral Research Program (JFM). 


\section{Structural Features that Optimize High Temperature Superconductivity}

J. D. Jorgensen ${ }^{1}$, D. G. Hinks ${ }^{1}$, O. Chmaissem ${ }^{1}$, D. N. Argyriou ${ }^{1}$, J.F. Mitchell ${ }^{1}$, and B. Dabrowski

${ }^{1}$ Materials Science Division and Science and Technology Center for Superconductivity, Argonne National Laboratory, Argonne, IL 60439, USA

2 Physics Department, Northern Illinois University, DeKalb, IL 60115, USA

Invited paper for the First Polish-US Conference on High Temperature Superconductivity, 11-15 September 1995, Wroclaw-Duszniki Zdr., Poland. Proceedings to be published by Springer-Verlag as a volume in their series "Lecture Notes in Physics."

(15 January 1996) 


\title{
Structural Features that Optimize High Temperature Superconductivity
}

\author{
$\therefore$ \\ J. D. Jorgensen ${ }^{1}$, D. G. Hinks ${ }^{1}$, O. Chmaissem ${ }^{1}$, D. N. Argyriou ${ }^{1}$, J. F. Mitchell ${ }^{1}$, \\ and B. Dabrowski ${ }^{2}$ \\ 1 Materials Science Division and Science and Technology Center for \\ Superconductivity, Argonne National Laboratory, Argonne, IL 60439, USA \\ 2 Physics Department, Northern Illinois University, DeKalb, II 60115, USA
}

\begin{abstract}
Studies of a large number of compounds fave provided a consistent picture of what structural features give rise to the highest $T_{c}$ 's in copper-oxide superconductors. For example, various defects can be introduced into the blocking layer to provide the optimum carrier concentration, but defects that form in or adjacent to the $\mathrm{CuO}_{2}$ layers will lower $\mathrm{T}_{c}$ and eventually destroy superconductivity. After these requirements are satisfied, the highest $T_{c}$ 's are observed for compounds (such as the $\mathrm{HgBa}_{2} \mathrm{Ca}_{n-1} \mathrm{Cu}_{\mathrm{n}} \mathrm{O}_{2 n+2+x}$ family) that have flat and square $\mathrm{CuO}_{2}$ planes and long apical $\mathrm{Cu}-\mathrm{O}$ bonds. This conclusion is confirmed by the study of materials in which the flatness of the $\mathrm{CuO}_{2}$ plane can be varied in a systematic way. In more recent work, attention has focused on how the structure can be modified, for example, by chemical substitution, to improve flux pinning properties. Two strategies are being investi-. gated: (1). Increasing the coupling of pancake vortices to form vortex.lines by shortening or "metallizing" the blocking layer; and.(2) the formation of defects that pin flux.
\end{abstract}

\section{Introduction}

The structural complexity of the copper-oxide high- $\mathrm{T}_{\mathrm{c}}$ superconductors provides the opportunity to optimize the superconducting properties. Over fifty distinct compounds have been discovered in the last ten years. For each of these, chemical substitution or variations in oxygen composition at a crystallographic site that supports . variable occupancy can be used to "tune" the properties. For a number of years, the primary goal of such studies has been to achieve a high superconducting transition temperature, $\mathrm{T}_{\mathrm{c}}$. Steady progress has been made, although one might argue that new record-high $\mathrm{T}_{c}$ 's were simply the result of exploring the variety of chemical compositions that could form rather than the result of a directed effort to achieve a crystal structure that had been predicted to yield a higher $T_{c}$. In the course of this work, however, it has become clear how $T_{c}$ is related to various structural features and there is consensus concerning what structures yield the best high- $T_{c}$ superconductors. A summary of what has been leamed is presented in this paper.

More recently attention has turned to how one might adjust the structural properties to improve the critical current behavior $\left(\mathrm{J}_{\mathrm{c}}\right)$ of these materials. [1] This work has been driven by the need to achieve better $J_{c}$ 's in order to use. high- $T_{c}$ materials in current carrying applications. The bulk $J_{c}$ of a conductor depends on both extrinsic proper- 
ties, such as grain alignment and the nature of grain boundaries, and on intrinsic properties, such as the flux pinning behavior of the material. Dramatic differences in the intrinsic flux pinning of the various compounds suggests that crystal structure, including both the "ideal" features of the structure and the presence of defects, can play an important role. For example, $\mathrm{YBa}_{2} \mathrm{Cu}_{3} \mathrm{O}_{6+x}$ (hereafter abbreviated as $\mathrm{Y}-123$ ) displays much better intrinsic flux pinning than $\mathrm{Bi}-\mathrm{Sr}-\mathrm{Ca}-\mathrm{Cu}-\mathrm{O}$ materials (BSCCO). However, the latter materials are preferred for wire applications because the grains align and form favorable grain boundaries for conduction during extrusion and firing processes. Clearly, if one could improve the intrinsic flux pinning behavior of BSCCO, the results would be of great importance. Recent work in several laboratories has focused on chemical substitution as a means of improving flux pinning behavior by modifying the crystal structure. "This paper will review some of this work and outline a strategy for improving flux pinning through chemical substitution:

\section{Optimizing $\mathbf{T}_{\mathrm{c}}$}

It was realized early in the study of high- $T_{c}$ materials that the superconductivity is a property of the $\mathrm{CuO}_{2}$ layers that are present in every high- $\mathrm{T}_{c}$ structure.[2] These $\mathrm{CuO}_{2}$ layers can occur singly or in groups separated by metal atoms such as $\mathrm{Y}$ or $\mathrm{Ca}$. The intervening space between these groups of layers, which we will call the blocking layer, can be filled with a wide variety of structural elements (e.g. $\mathrm{Cu}-\mathrm{O}$ chains, T1-O layers, $\mathrm{Bi}-\mathrm{O}$ layers, $\mathrm{Hg}-\mathrm{O}$ layers, $\mathrm{CO}_{3}$ ions, etc.). This flexibility is what has given rise to the large number of high- $\mathrm{T}_{\mathrm{c}}$ compounds now known. For any of these compounds, certain conditions must be satisfied to achieve superconductivity.

First, the carrier concentration in the $\mathrm{CuO}_{2}$ planes must be adjusted to the optimal level. $[3,4,5,6,7]$ This is typically done by chemical substitution on a metal site (other than a $\mathrm{Cu}$ site in the $\mathrm{CuO}_{2}$ layers) or by varying the oxygen content in a crystallographic site that supports variable occupancy. $[2,8,9,10]$ For example; the $T_{c}$ of $\mathrm{La}_{2-\mathrm{x}} \mathrm{Sr}_{\mathrm{x}} \mathrm{CuO}_{4}$ (LSCO) varies with the amount of $\mathrm{Sr}^{2+}$ 'substituted on the $\mathrm{La}^{3+}$ site, with the maximum $T_{c}$ achieved for $x=0.15$. $[5,11]$ For low values of $x, T_{c}$ decreases and the material enters an insulating state; while for values of $x$ higher than the optimum (near 0.15). $T_{c}$ decreases and the material goes to a nonsuperconducting metallic state. This behavior appears to be true for all copper-oxide high- $\mathrm{T}_{c}$ materials $[3,4,7$, $12,13]$, but in some compounds limitations in what compositions will form prevents the whole range of behavior from being accessed. For example, the $\mathrm{YBa}_{2} \mathrm{Cu}_{3} \mathrm{O}_{6+x}$ compound exhibits its maximum $T_{c}$ near the maximum oxygen concentration of 7 oxygen atoms per formula unit and is under doped for lower oxygen contents $[14,15$, 16], while the $\mathrm{Tl}_{2} \mathrm{Ba}_{2} \mathrm{CuO}_{6+x}$ compound exhibits its maximum $\mathrm{T}_{\mathrm{c}}$ for $\mathrm{x}$ near zero and is over doped as the oxygen content increases. $[17,18]$

The second requirement is that there be no defects in or near the $\mathrm{CuO}_{2}$ layers: Defects such as oxygen atoms next to the $\mathrm{Y}$ or $\mathrm{Ca}$ atoms that separate adjacent $\mathrm{CuO}_{2}$ layers have been shown to lower $T_{c}$ and destroy. superconductivity. $[2,8,9,19]$ Substitution of other metal atoms (e.g., $\mathrm{Ni}, \mathrm{Fe}$, or $\mathrm{Zn}$ ) on the $\mathrm{Cu}$ sites in the $\mathrm{CuO}_{2}$ layers in very low concentrations also destroys superconductivity. $[20,21,22]$ Thus, chemical variables in the blocking layer are typically used to control $\mathrm{T}_{\mathrm{c}}$. (It is possi- 
ble to modify carrier concentration with appropriate chemical substitution at the Y/Ca site. $[12,23,24])$

After these requirements are satisfied, there is a maximum $T_{c}$ possible for each compound. These maximum $\mathrm{T}_{c}$ 's vary widely (e.g., about $40 \mathrm{~K}$ for LSCO[11] vs. 90 $\mathrm{K}$ for $\mathrm{Y}-123[15]$ and $135 \mathrm{~K}$ for $\mathrm{Hg}-1223[25,26])$, suggesting that structural properties control the maximum $T_{c}$ that can be achieved. Comparison of the structures of a large number of copper-oxide superconductors has led to the conclusion that the highest $\mathrm{T}_{c}$ is achieved in structures with flat and square $\mathrm{CuO}_{2}$ layers (which implies a tetragonal crystal structure).and long apical copper-oxygen bonds connecting to these layers. $[26,27,28,29,30,31]$ The $\mathrm{HgBa}_{2} \mathrm{Ca}_{n-1} \mathrm{Cu}_{n} \mathrm{O}_{2 n+2+x}$ (HBCCO). compounds, which have the highest $T_{c}$ 's yet observed for $n=1,2$, and 3 layer compounds, also have the flattest $\mathrm{CuO}_{2}$ layers and the longest $\mathrm{Cu}-\mathrm{O}$ apical bond lengths.[26, 28] The relevant structural parameters are lister in Table 1.

Table 1. Copper-oxygen apical bond length $(\mathrm{Cu}-\mathrm{O})$ and buckling angle of the $\mathrm{CuO}_{2}$ plane $(\mathrm{Cu}-\mathrm{O}-\mathrm{Cu})$ for $\mathrm{HgBa}_{2} \mathrm{Ca}_{n-1} \mathrm{Cu}_{n} \mathrm{O}_{2 n+2+x}$ compounds.[26, 27, 28]

\begin{tabular}{llll}
\hline No. of layers, $n$ & $\mathrm{~T}_{\mathrm{c}}(\mathrm{K})$ & $\mathrm{Cu}-\mathrm{O}(\AA)$ & $\mathrm{Cu}-\mathrm{O}-\mathrm{Cu}\left({ }^{\circ}\right)$ \\
\hline 1 & 95 & 2.78 & 180 \\
2 & 126 & 2.78 & 179 \\
3 & 135 & 2.74 & 178 \\
\hline
\end{tabular}

The systematic correlation between buckling angle (the $\mathrm{Cu}-\mathrm{O}-\mathrm{Cu}$ angle in the $\mathrm{CuO}_{2}$ plane), $\mathrm{Cu}-\mathrm{O}$ apical bond length, and $\mathrm{T}_{c}$ for compounds with two $\mathrm{CuO}_{2}$ layers (for which the most data are available) is shown in Fig. 1. For consistency, the figure is based on data for compounds in which $\mathrm{Ca}$ separates the two $\mathrm{CuO}_{2}$ layers and the composition (carrier concentration) has been optimized to achieve the maximum $\mathrm{T}_{\mathbf{c}}$ for each compound. $[15,19,28,32,33,34]$ For these compounds, the correlation between $T_{c}$ and the buckling angle or apical bond distance is clear. However, $Y$ 123[15], $\mathrm{YBa}_{2} \mathrm{Cu}_{4} \mathrm{O}_{8}(\mathrm{Y}-124)[35,36]$, and $\mathrm{Pb}_{2} \mathrm{Sr}_{2} \mathrm{YCu}_{3} \mathrm{O}_{8}$ (PSYCO)[37] (and HBCCO compounds at high pressure, which will be discussed later) are exceptions. We believe that the most important difference for these compounds is the presence of metallic copper in the blocking layer as well as in the $\mathrm{CuO}_{2}$ planes. The importance of this structural feature for obtaining high $\mathrm{T}_{c}$ will be discussed later.

The apical bond distance and buckling angle are closely related variables. This is illustrated in Fig. 2, where the apical distance is plotted vs. the buckling angle for the same compounds. Short apical distances lead to buckled $\mathrm{CuO}_{2}$ planes because of oxygen-oxygen repulsion, while long apical distances allow the planes to approach a nearly flat condition.

An instructive confirmation of the relationship between buckling angle and $\mathrm{T}_{\mathrm{c}}$ comes from the investigation of a single compound in which the buckling angle can be varied at constant carrier concentration. Such experiments can be done in the $\mathrm{La}_{2-\mathrm{x}} \mathrm{M}_{\mathrm{x}} \mathrm{CuO}_{4}\left(\mathrm{M}=\mathrm{Sr}, \mathrm{Ba}, \mathrm{Ca}, \mathrm{Nd}\right.$, etc.) system. In this structure, buckling of the $\mathrm{CuO}_{2}$ 


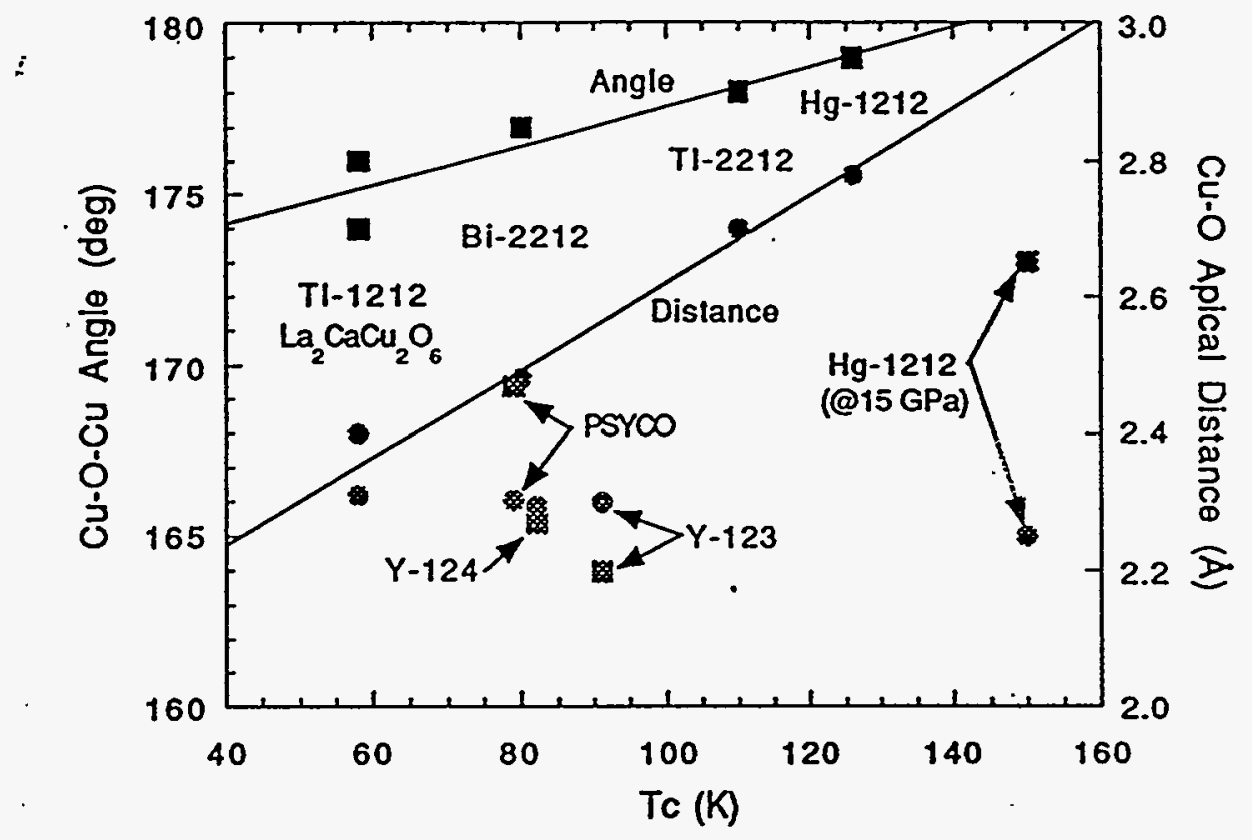

Fig. 1. Relationship between $\mathrm{T}_{c}$ and the $\mathrm{Cu}-\mathrm{O}-\mathrm{Cu}$ buckling angle for the $\mathrm{CuO}_{2}$ planes and the $\mathrm{Cu}-\mathrm{O}$ apical bond distance for compounds with two $\mathrm{CuO}_{2}$ layers. Square symbols are angles; round symbols are distances.[data from Refs. 15, 19,.28, 32, 33, 34]

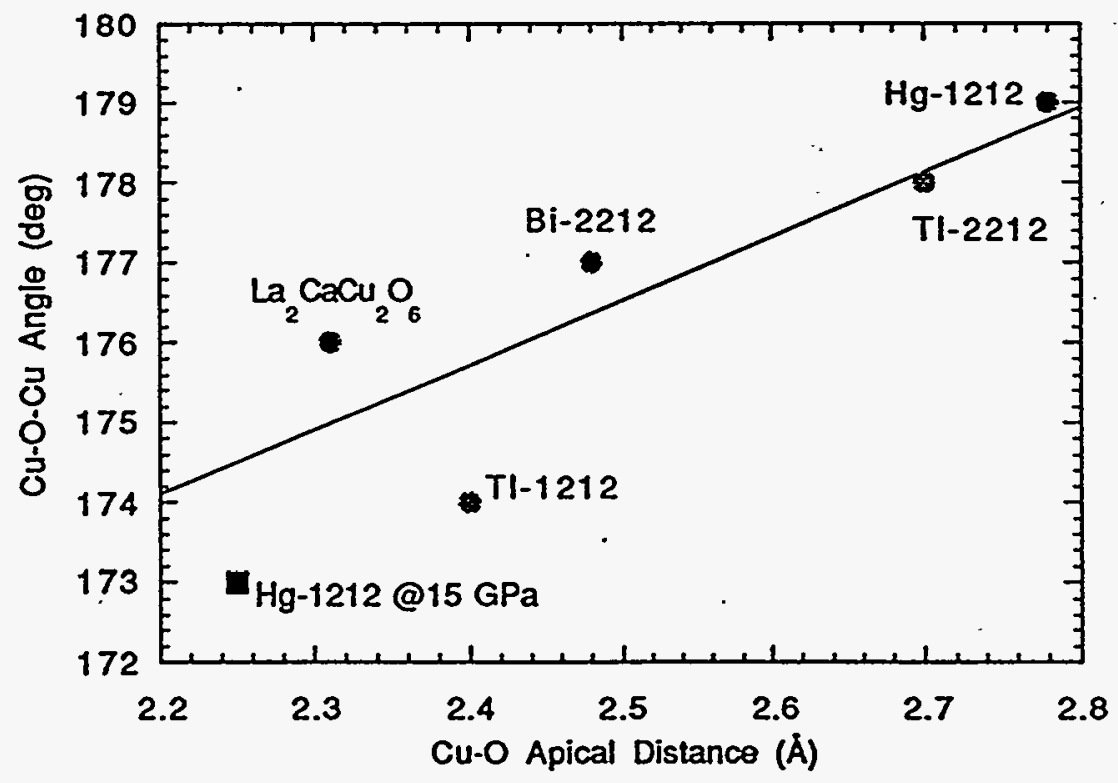

Fig. 2. $\mathrm{Cu}-\mathrm{O}$ apical bond distance vs. $\mathrm{Cu}-\mathrm{O}-\mathrm{Cu}$ buckling angle for compounds with two $\mathrm{CuO}_{2}$ layers where $\mathrm{Ca}$ separates the two layers. 
plane results from a nearly rigid coordinated tilting of $\mathrm{CuO}_{6}$ octahedra. The degree of tilting (and buckling) can be varied by the application of hydrostatic pressure or by substitutional chemistry on the La site. The application of pressure reduces the buckling angle and raises $T_{c}$. [38] For a composition with the maximum $T_{c},\left(T_{c} \approx 40 \mathrm{~K}\right.$ for $x=0.15 \mathrm{Sr}$ substitution), $T_{c}$ increases systematically as the buckling angle is reduced by the application of pressure.[39] Eventually, the buckling angle becomes $180^{\circ}$ (flat $\mathrm{CuO}_{2}$ planes), resulting in a transformation from orthorhombic to tetragonal symmetry. Further increases in applied pressure do not raise $T_{\text {.c }}$.

Comparison of the $\mathrm{Ca}$ substituted system with the $\mathrm{Sr}$ substituted system leads to the same conclusion. At the same carrier concentration $(x=0.15)$ the Ca substituted system has a larger amount of plane buckling and a lower $T_{c}$. [40] Through the use of the combined substitution of $\mathrm{Nd}, \mathrm{Ca}$, and $\mathrm{Sr}$ on the La site, a wide range of buckling angles can be achieved at constant carrier concentration.[41] Such experiments have yielded the quantitative relationship between buckling angle and $T_{c} \cdot T_{c}$ decreases 20 $\mathrm{K}$ for an increase in the buckling angle of $8^{\circ}$.

The highest $T_{c}$ 's yet achieved were observed by applying pressure to the $\mathrm{HBCCO}$ compounds. $[42,43,44,45]$ By the application of pressures on the order of 15-30 $\mathrm{GPa}$, an increase of nearly $25 \mathrm{~K}$ is achieved for the $T_{c}$ 's of the $n=1,2$, and $3 \mathrm{com}$ pounds; giving a record-high $\mathrm{T}_{\mathrm{c}}$ for $\mathrm{Hg}-1223$ of $160 \mathrm{~K}$ at $\sim 20 \mathrm{GPa}$.[43] The structures of these compounds at high pressure are particularly interesting. Fig. 3 compares the structure of $\mathrm{Hg}-1212$ at $15 \mathrm{GPa}$ with the structure at ambient pressure.[46]

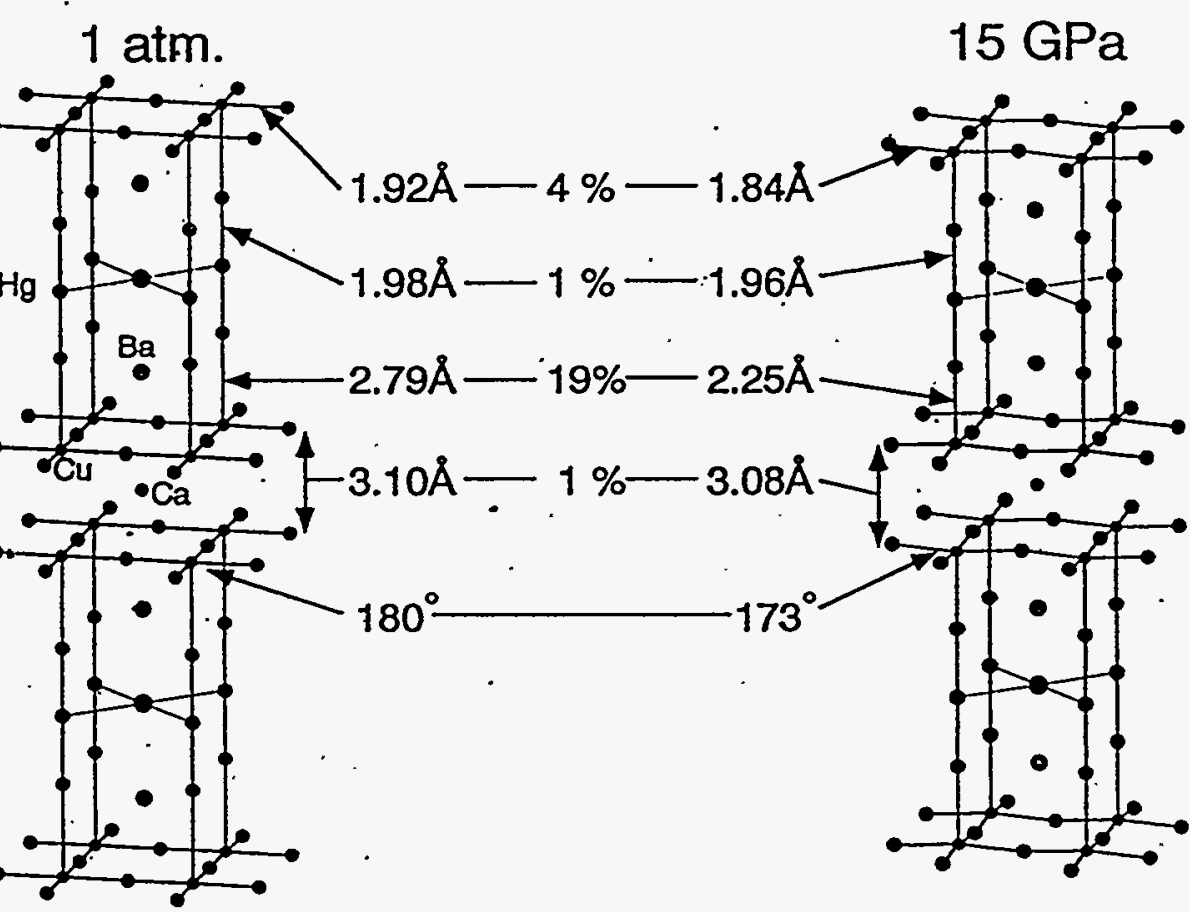

Fig. 3. Comparison of the structures of $\mathrm{Hg}-1212$ at ambient pressure and $15 \mathrm{GPa}$. Values for selected bond lengths and angles, and the percentage change over this pressure range, are shown. The $15 \mathrm{GPa}$ structure is extrapolated from accurate measurements at $0.6 \mathrm{GPa}$. 
(The most accurate structural data at high pressure are obtained for the one- and two- layer compounds because impurity phases in samples of the three-layer compound reduce the precision available from structural refinements.) The largest pressureinduced structural change is a dramatic shortening of the apical $\mathrm{Cu}-\mathrm{O}$ bond, from 2.79 to $2.25 \AA$. As would be expected, this is accompanied by a buckling of the $\mathrm{CuO}_{2}$ planes. The relationship between apical bond length and plane buckling angle nicely. follows the behavior observed for other compounds, as shown in Fig. 2.

Clearly, the large pressure-induced increase in $T_{c}$ cannot be explained in terms of the systematic relationship between buckling angle, apical bond length, and $\mathrm{T}_{c}$ presented in Fig. 1. One important difference between the $\mathrm{Hg}-1212$ structure at high.pressure and the other two-layer structures is the length of the in-plane $\mathrm{Cu}-\mathrm{O}$ bond. Pressure shortens this bond to $1.84 \AA$ for $\mathrm{Hg}-1212$ at $15 \mathrm{GPa}$, whereas it is around $1.92 \AA$ for all of the two-layer compound 1 at ambient pressure. This shortened $\mathrm{Cu}-\mathrm{O}$ in-plane bond has important implications for the electronic structure, which remains very two dimensional, with a well-defined van Hove singularity in the density of states, even though the apical bond length is dramatically shortened by pressure. $[47,48]$ A peak in the density of states resulting from the van Hove singularity is thought to correspond to the optimum doping level. $[49,50,51,52]$ We speculate, however, that another difference in the electronic structure may be more important. Band structure calculations for the high-pressure structures. show that the application of pressure either produces or significantly increases the overlap of a band involving $\mathrm{Hg}$ with the Fermi energy, resulting in an electronic structure where there are more carriers associated with the $\mathrm{Hg}-\mathrm{O}$ layer. $[47,48,53]$ These calculations are not accurate enough to determine exactly when the $\mathrm{Hg}-\mathrm{O}$ layer first becomes metallic because of the difficulty of accurately specifying the electron count for these compounds. Experimentally, variable oxygen content at a site in the $\mathrm{Hg}$ layer is used to set the carrier concentration. $[25,26,27,28,30,54,55,56,57,58]$ However, judging from the large differences between optimal oxygen contents for samples made by different procedures in different laboratories, one or more additional defects that have not yet been identified in structural studies, also control the carrier concentration. $[27,59,60]$

If our hypothesis is correct, the record high $\mathrm{T}_{c}$ 's for $\mathrm{HBCCO}$ compounds at high pressure result from metallization of the blocking layer. At ambient pressure, these compounds fall on the systematic curves for $T_{c}$ vs. buckling angle and apical bond distance along with other compounds that have insulating blocking layers (Fig. 1). When pressure is applied, the blocking layer becomes more metallic and the HBCCO compounds display behavior analogous to the Y-123, Y-124, and PSYCO compounds, which have metallic copper in their blocking layers and are exceptions to the systematic behavior.

\section{Optimizing $\mathbf{J}_{\mathbf{c}}$}


compounds with the highest $T_{c}$ 's ofter do not exhibit high $J_{c}$ 's.[1] For film applications, $Y-123$ is the most widely used compound. High $\mathrm{J}_{\mathrm{c}}$ 's can be achieved through proper processing; such as Ion Beam Assisted Deposition (IBAD). BSCCO is the preferred material for bulk applications. Because of the micaceous nature of the material, the crystallites cleave and orient in a favorable way when wires, consisting of BSCCO 
powder in metal sheaths, are drawn. Unfortunately, the $\mathrm{J}_{c}$ is limited by the relatively . poor flux pinning of BSCCO. Relatively poor flux pinning of the HBCCO compounds limits their usefulness for applications.[61, 62, 63, 64]

- Work to improve $J_{c}$ has concentrated for some time on issues such as achieving favorable orientation of crystalline grains, for example, by the cleaving process that occurs naturally in BSCCO or the recently developed IBAD process for Y-123 films.[1] Considerable effort has been spent investigating the effects of grain boundaries, which act as weak links in the conduction process. Work to understand and improve the intrinsic flux pinning behavior of copper-oxide superconductors began more recently. Some of the first work focused on ways to improve flux pinning in HBCCO compounds. Shimoyama et al. reported significant improvements in the flux pinning of $\mathrm{HBCCO}$ compounds where $\mathrm{Hg}$ has been partially replaced by $\mathrm{Re}$ or $\mathrm{Cr}$ and Ba replaced by Sr.[65, 66, 67] These compounds also exhibit improved chemical: stability.

These early studies of chemically substituted HBCCO compounds have provided.a framework for.understanding how flux pinning might be improved through chemical substitution. Shimoyama et al., have argued that at least two features of the modified structures may enhance flux pinning: (1) The substitution of $\mathrm{Sr}$ for $\mathrm{Ba}$ significantly. shortens the blocking layer distance $[65,67]$, and (2) the substitution (e.g., $\mathrm{Re}$ or $\mathrm{Cr}$ ) at the $\mathrm{Hg}$ site may make the blocking layer more metallic.[68] Both of these are thought to increase the coupling of pancake-like vortices to form vortex lines along the $c$ axis. This increases flux pinning because fewer pinning centers are required to pin extended vortex lines than to pin an equivalent amount of flux in the form of individual pancake vortices. $[69,70]$ In a recent paper, Chmaissem et al. also explored the possibility that chemical substitution ( $\mathrm{Cr}$ for $\mathrm{Hg}$ ) in $\mathrm{Hg}-1201$ can form extended defects that could act as pinning centers.[71] We have recently performed some of the first detailed structural studies of these chemically substituted HBCCO compounds. A brief review of the findings will be given here.

The most successful method to date for shortening the blocking layer has been the full substitution of the smaller $\mathrm{Sr}$ ion for Ba.[65] It was found, however, that this substitution could not be achieved unless the $\mathrm{Hg}$ site was also partially substituted by $\mathrm{Re}$ or $\mathrm{Cr}$ and part of the $\mathrm{Ca}$ separating $\mathrm{CuO}_{2}$ layers was substituted by $\mathrm{Y} .[65,66,67$; 71] High pressure synthesis methods were used by Yamaura, et al. to synthesize compounds in which this substitution on the $\mathrm{Ca}$ site was not required.[68] . The structures of these materials, $\mathrm{Hg}_{1-x} \mathrm{Re}_{x} \mathrm{Sr}_{2} \mathrm{Ca}_{n-1} \mathrm{Cu}_{n} \mathrm{O}_{2 n+2+\delta}$ (for $\mathrm{n}=2$ and 3 , and $\mathrm{x}=0.25$ ), have been determined by neutron powder diffraction.[72] The portions of the structures containing the Re substitution are shown in Fig. 4.

When $\mathrm{Re}$ substitutes at the $\mathrm{Hg}$ site, it achieves coordination to six nearby oxygen atoms by incorporating four additional oxygen atoms (O3) into the $\mathrm{Hg} / \mathrm{Re}$ plane (in addition to the two apical oxygen atoms, $\mathrm{O} 2^{\prime}$ ). This sixfold coordination of $\mathrm{Re}$ to oxygen is typical of $\mathrm{Re}(\mathrm{VI})$ compounds. The perovskite $\mathrm{ReO}_{3}$, where $\mathrm{Re}$ has the same coordination, is one of the most metallic oxides. One might expect the Re substitution to make the blocking layer more metallic, but no experiments have been done to characterize how the electronic character of the blocking layer is modified by the Re substitution. One oxygen site per formula unit is available in the $\mathrm{Hg} / \mathrm{Re}$ plane, setting a conceptual solubility limit for $R e$ of $x=0.25$, which is observed in synthesis experiments. The substitution of $\mathrm{Sr}$ for $\mathrm{Ba}$ shortens the blocking layer by about $0.8 \AA$, as shown in Table 2 . The improvement in flux pinning is characterized by measuring the irreversibility field as a function of temperature, as shown in Fig. 5 
for $\mathrm{Hg}-1223$. The chemically substituted compound has a lower $\mathrm{T}_{\mathrm{c}}$ (by about $15 \mathrm{~K}$ ), but a higher irreversibility field at any temperature below about $115 \mathrm{~K}$.

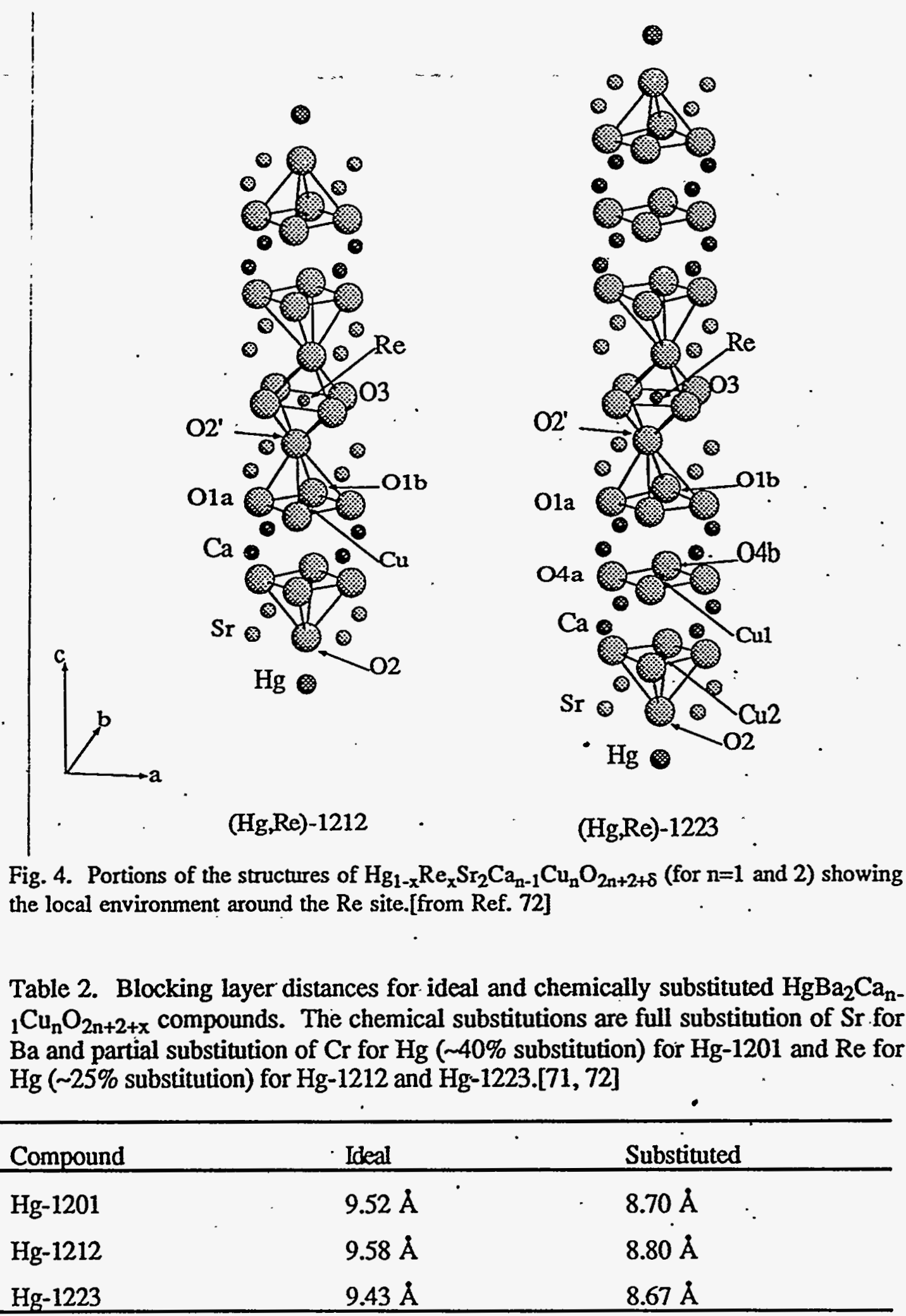




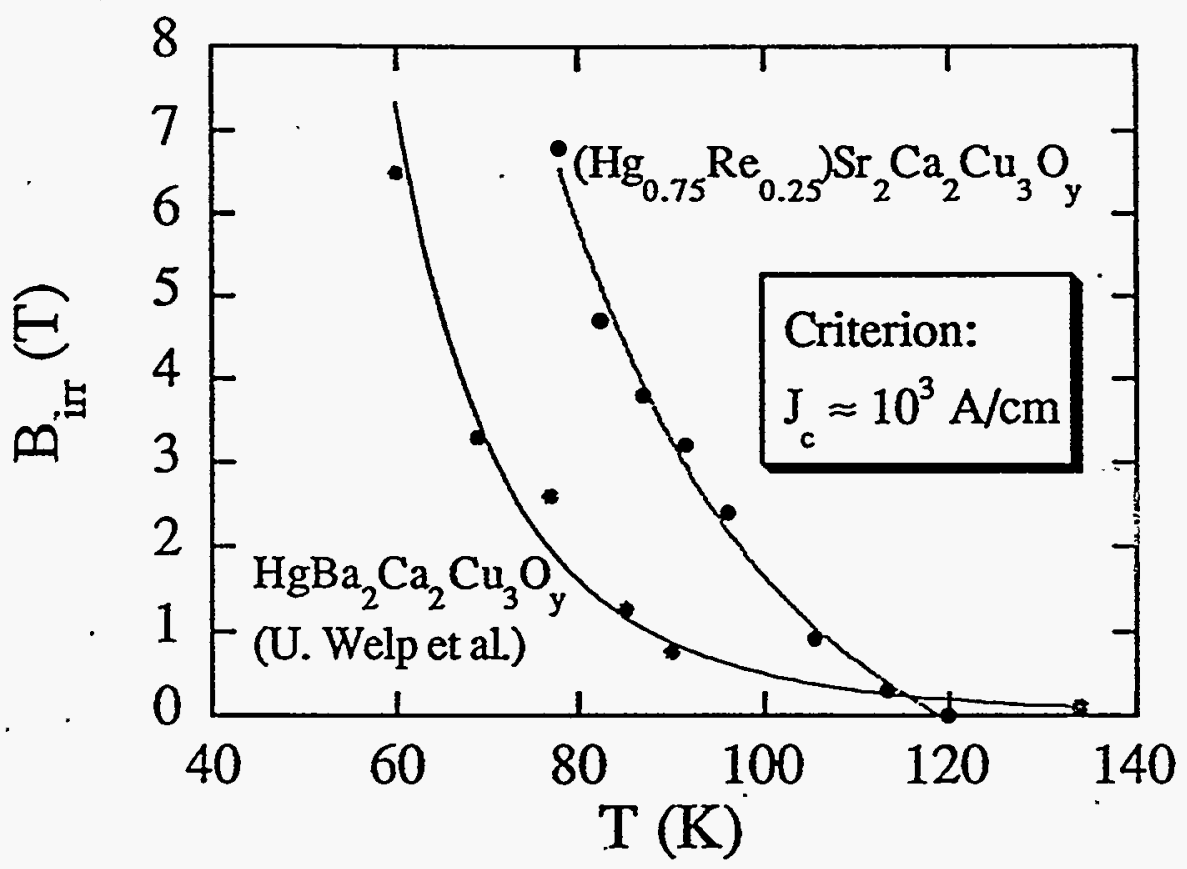

Fig. 5. Irreversibility fields vs. temperature for $\mathrm{HgBa}_{2} \mathrm{Ca}_{2} \mathrm{Cu}_{3} \mathrm{O}_{8+\delta}$ and $\mathrm{Hg}_{0.75} \mathrm{Re}_{0.25} \mathrm{Sr}_{2} \mathrm{Ca}_{2} \mathrm{Cu}_{3} \mathrm{O}_{8+\delta}$.[from Ref. 72]

The shortening of the blocking layer is thought to play a significant role in the improvement in flux pinning. : Shimoyama, et al. have found a systematic relationship between the blocking layer distance and the irreversibility behavior. However, in other recent experiments, Shimoyama, et al. have used high-pressure synthesis techniques to partially substitute $\mathrm{Cr}, \mathrm{Mo}$, or $\mathrm{Re}$ on the $\mathrm{Hg}$ site without the replacement of $\mathrm{Ba}$ by Sr.[65] These compounds also show enhanced flux pinning, even though the blocking layer is not shortened; in fact, it is lengthened in some compounds. These experiments emphasize the need to investigate other structural effects on flux pinning, such as metallization of the blocking layer and the formation of defects that pin flux:

Structural studies of the $\mathrm{Hg}_{1-x} \mathrm{Cr}_{x} \mathrm{Sr}_{2} \mathrm{CuO}_{4+\delta}$ system illustrate how chemical substitution can lead to the formation of extended defects. The structure of this compound, determined by neutron powder diffraction, is shown in Fig. 6.[71] Sr substitution at the Ba site leads to a shortening of the blocking layer distance of about $0: 8 \AA$, as was seen in the two- and three-layer compounds (see Table 2). $\mathrm{Cr}$ substitutes for $\mathrm{Hg}$, but is displaced off the ideal site to allow tetrahedral coordination to four oxygen atoms. Two of these are the original apical oxygen atoms $(\mathrm{O} 2)$ which have been displaced to form an appropriate bond distance to $\mathrm{Cr}$ (the $\mathrm{O} 2$ ' site) and two additional oxygen atoms $(\mathrm{O} 3)$ are incorporated into the $\mathrm{Hg} / \mathrm{Cr}$ plane. The $\mathrm{Cu}-\mathrm{O}^{\prime}$ distance is $3.13 \AA$. This apical oxygen atom has essentially been removed from the $\mathrm{CuO}_{6}$ octahedron. The $\mathrm{Cu}$ atom displaces towards the remaining apical oxygen $(\mathrm{O} 2)$ to form a rather short bond $(2.25 \AA)$. Thus, one effect of the $\mathrm{Cr}$ substitution is to convert elongated $\mathrm{CuO}_{6}$ octahedra to $\mathrm{CuO}_{5}$ pyramids. Energetically, the formation of four-coordinated 
(a)

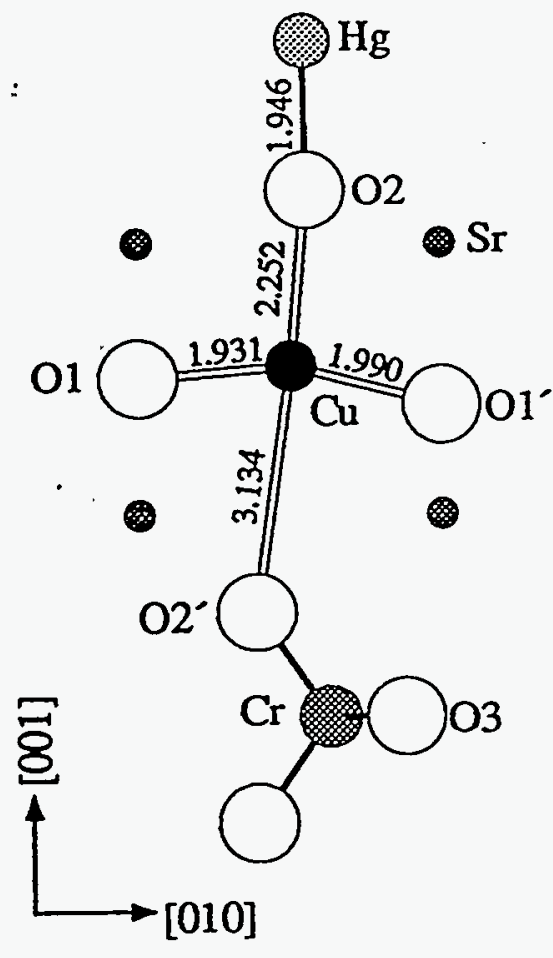

(b)

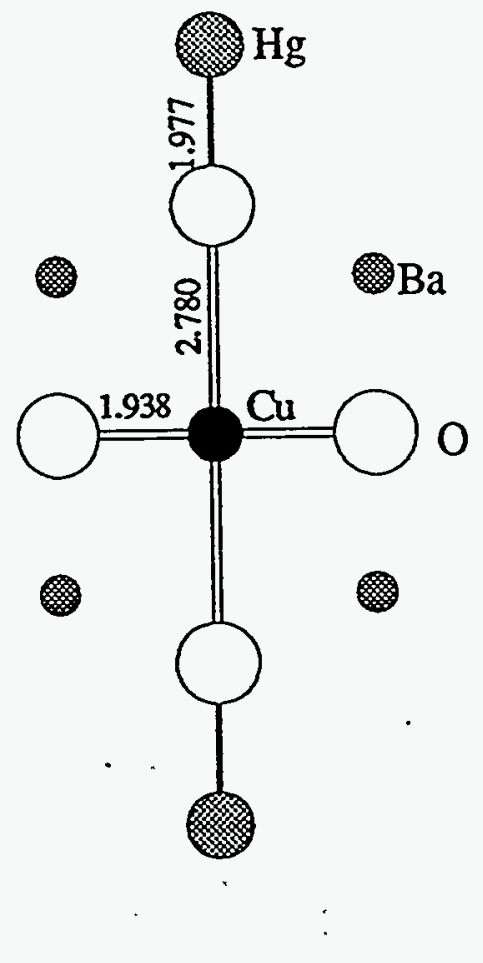

Fig. 6. Portion of the structure of $\mathrm{Hg}_{1-x} \mathrm{Cr}_{x} \mathrm{Sr}_{2} \mathrm{CuO}_{4+\delta}$ showing the local configuration . around a $\mathrm{Cr}$ site (a) compared to the ideal $\mathrm{Hg}-1201$ structure (b).[from Ref. 71] . .

$\mathrm{Cu}^{2+}$. is unlikely. For this reason, $\mathrm{Cr}$ and $\mathrm{Hg}$ tend to alternate along the c.axis, leading to a doubling of the unit cell in this direction.

All possible $\mathrm{O} 3$ oxygen sites in the $\mathrm{Hg} / \mathrm{Cr}$ plane will be occupied for a conceptual Cr substitution limit of $50 \%$. In experiments, it has been found to be difficult to exceed about $40 \%$ substitution. Cr atoms tend to cluster in the $\mathrm{Hg} / \mathrm{Cr}$ plane. As additional $\mathrm{CrO}_{4}$ units are added to these clusters, they must orient so that the associated O3 oxygen atoms can occupy available sites as shown in Fig. 7. Ultimately, the size of these clusters is limited by the availability of possible sites for the $\mathrm{O} 3$ atoms, leading to a maximum cluster size of about 2.5 unit cells (see Fig. 7). This ordering effect leads to an incommensurate supercell of approximate dimensions $5 \mathrm{a} \times 5 \mathrm{a} \times 2 \mathrm{c}$, which has been observed in electron diffraction measurements. In this supercell, $\mathrm{Cr}$ and $\mathrm{Hg}$-rich regions alternate in all three directions, but the orientational frustration of the $\mathrm{CrO}_{4}$ units as they cluster (as illustrated in Fig. 7) leads to considerable disorder within the supercell.

The existence of this supercell provides a structural dimension that allows defects of a size that could be effective for flux pinning. It is important to consider what kinds of defects can form for $\mathrm{Cr}$ concentrations below the solubility limit of $50 \%$. In such a case, extended $\mathrm{Hg}$-rich clusters will form. A particularly interesting aspect of these clusters is that they give rise to columns of $\mathrm{CuO}_{6}$ octahedra along the $\mathrm{c}$ axis, embedded in a structure that consists mainly of $\mathrm{CuO}_{5}$ pyramids, as shown in Fig. 8. 


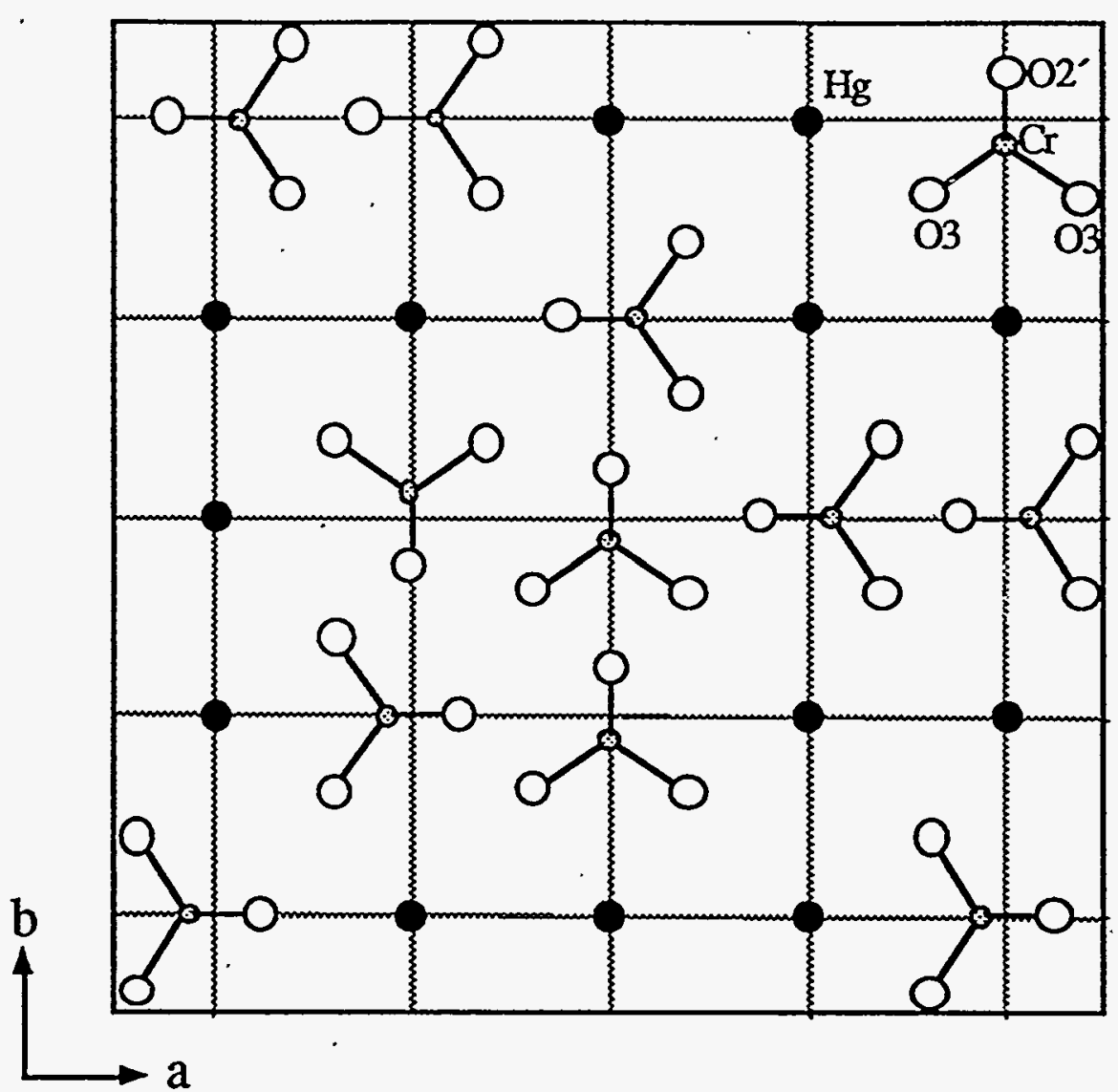

Fig. 7. Representation of one layer of the $\mathrm{Hg} / \mathrm{Cr}$ plane of $\mathrm{Hg}_{1-\mathrm{x}} \mathrm{Cr}_{\mathrm{x}} \mathrm{Sr}_{2} \mathrm{CuO}_{4+\delta}$ showing a possible arrangement of $\mathrm{CrO}_{4}$ units to. form a cluster of approximate dimensions $2.5 \mathrm{a}$. Cluster size is limited by the availability of sites for 03 atoms.[from Ref. 71]

Although no measurements have yet been done to determine whether these defects are effective for pinning flux, it is encouraging to observe that defects of a favorable size (comparable to the coherence length) can be produced by chemical substitution. Based on the present observations, it is likely that extended defects will also form in the limit of low $\mathrm{Cr}$ concentration. If $\mathrm{CrO}_{4}$ units tend to cluster, as has been observed for concentrations near $50 \%$, the resulting defects would be islands of $\mathrm{Cr}$ in the $\mathrm{Hg} / \mathrm{Cr}$ plane about $10 \AA$ (2.5a) in diameter. In this region, $\mathrm{CuO}_{6}$ octahedra with long apical bonds would be converted to $\mathrm{CuO}_{5}$ pyramids with short apical bonds, locally disrupting the superconducting properties of the $\mathrm{CuO}_{2}$ plane to form the pinning center.

\section{A Strategy for Optimization}

To produce the ideal material for applications, one would like to optimize both $T_{c}$ and $\mathrm{J}_{c}$. A summary of the methods for doing this is given in Table 3. Shortening the blocking layer will improve flux pinning, but if it is done in a way that leads to a shorter apical $\mathrm{Cu}-\mathrm{O}$ bond, $\mathrm{T}_{c}$ will likely be lowered. This effect is observed in the chemically substituted $\mathrm{HBCCO}$ compounds, where $\mathrm{T}_{c}$ 's are typically $15 \mathrm{~K}$ or more 


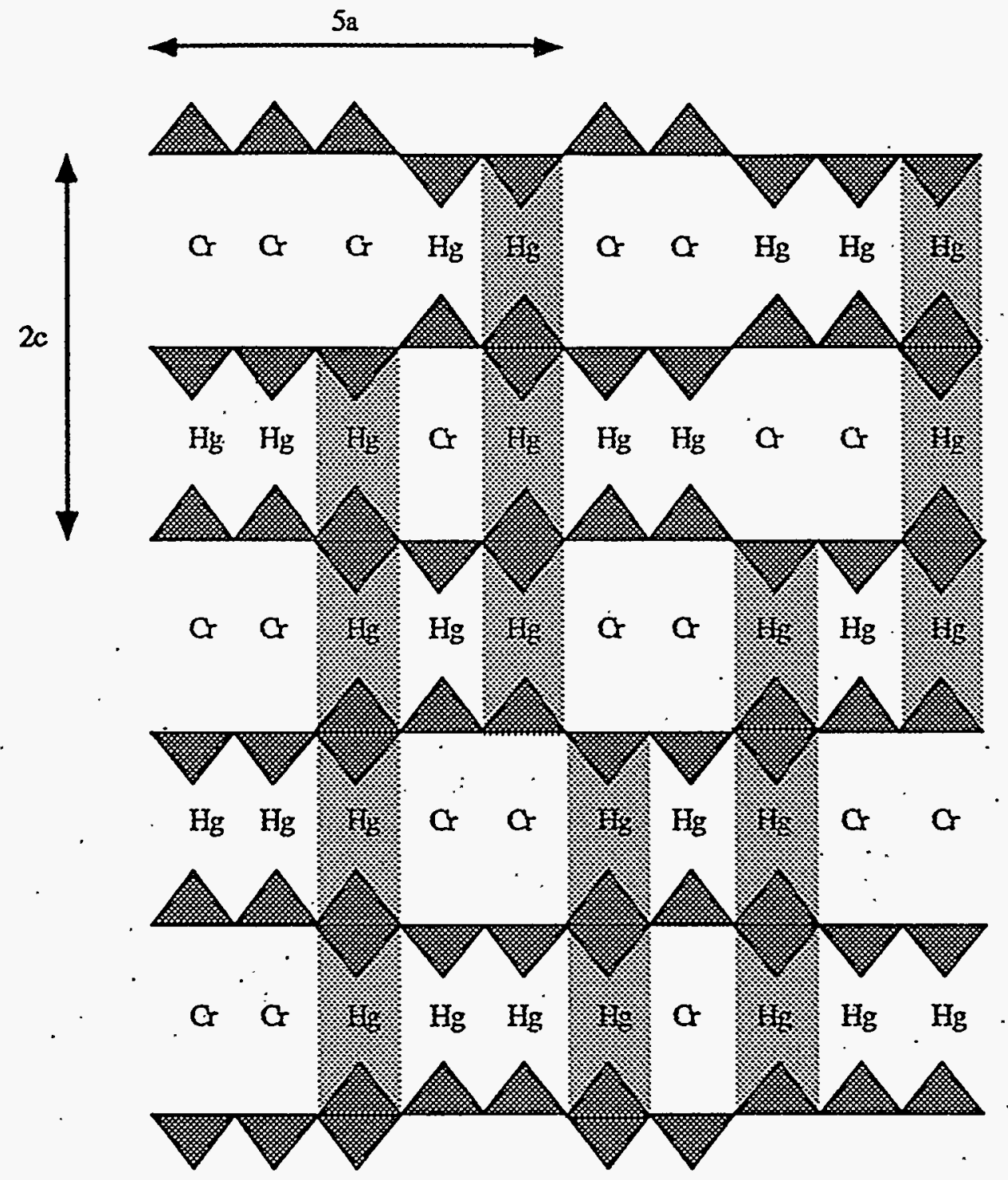

Fig. 8. Representation of the columns of $\mathrm{CuO}_{6}$ octahedra along the $\mathrm{c}$ axis that are expected to form for $\mathrm{Cr}$ concentrations below 50\%.[from Ref. 71]

lower than for the ideal compounds.[71, 72] We propose that metallizing the blocking layer will raise $T_{c}$ and improve flux pinning at the same time. Chemical substitutions that produce this effect should be explored to verify whether this hypothesis holds. Additionally, there must be defects that will pin flux. Our work suggests that it may be possible to produce favorable defects (having dimensions approaching the coherence length) by chemical means. If these defects are in the blocking layer rather than in the $\mathrm{CuO}_{2}$ planes, the effect on $\mathrm{T}_{c}$ should not be too severe, but, clearly, the defects must perturb superconductivity locally to pin flux. It is also important to correctly adjust the concentration of such defects. 
Table 3. Possible methods for structurally optimizing $T_{c}$ and $J_{c}$.

\begin{tabular}{lll}
\hline Shorten blocking layer & Effect on $\mathrm{T}_{c}$ & $\begin{array}{l}\text { Short apical Cu-O bond on } \mathrm{J}_{c} \\
\text { lowers } \mathrm{T}_{c}\end{array}$ \\
Metallize blocking layer & $\begin{array}{l}\text { Metallic blocking layer } \\
\text { raises } \mathrm{T}_{c}\end{array}$ & $\begin{array}{l}\text { Short blocking layer } \\
\text { improves flux pinning }\end{array}$ \\
Insert pinning defects & $\begin{array}{l}\text { Metallic blocking. layer } \\
\text { improves flux pinning } \\
\text { Defects in the wrong site } \\
\text { lower } \mathrm{T}_{c}\end{array}$ & $\begin{array}{l}\text { Defects of the proper size } \\
\text { can pin flux }\end{array}$ \\
\hline
\end{tabular}

\section{Conclusions}

The desire to optimize high- $\mathrm{T}_{c}$ materials for applications has motivated investigations of how both $\mathrm{T}_{c}$ and $\mathrm{J}_{\mathrm{c}}$ might be controlled by chemical/structural methods. A considerable data base, coming from years of work on the relationship between $T_{c}$ and structure, has led to a consensus of what structural features lead to the highest $T_{c}$. For compounds where the blocking layer is an insulating charge reservoir, there is a clear correlation between $\mathrm{T}_{c}$ and buckling (or corrugation) of the $\mathrm{CuO}_{2}$ plane and the apical $\mathrm{Cu}-\mathrm{O}$ bond length. Flat and square $\mathrm{CuO}_{2}$ planes and long apical bonds yield the highest $T_{c}$ 's. Compounds like $Y-123, Y-124$, and PSYCO, which seem to violate these rules, suggest that $T_{c}$ will be even higher if the blocking layer is metallic. High pressure studies of HBCCO compounds seem to confirm this view. Thus, the highest possible $\mathrm{T}_{c}$ would be observed in a compound with flat and square $\mathrm{CuO}_{2}$ planes, long apical $\mathrm{Cu}-\mathrm{O}$ bonds, and a metallic blocking layer. No compound yet discovered (including the HBCCO compounds at high pressure) combines all of these features. Thus, $\mathrm{T}_{c}$ 's even higher than $160 \mathrm{~K}$ may be possible through creative chemistry if the desired structural features can be achieved.

Work to increase $\mathrm{J}_{c}$ by improving the intrinsic flux pinning properties of the materials is still in its infancy. Initial studies indicate that structural properties can have a - significant effect on flux pinning. At least three strategies look promising. The first two focus on improving the coupling along the $c$ axis by shortening the blocking layer or metallizing the blocking layer. The third strategy is to devise chemical methods for creating defects that are effective for pinning flux. Experiments to date have focused on compounds in which more that one of these effects may be present at the . same time. It will be important in the future to investigate each effect individually. In the long term, the goal of such work will be to optimize both $T_{c}$ and $J_{c}$ at the same time. It is already clear that significant progress toward this goal is likely.

Acknowledgments. The authors wish to thank K. Kishio, Y. Shimoyama, K. Yamaura, Z. Hiroi, and M. Takano for collaboration and discussion on materials properties that enhance flux pinning. This work was supported by the U. S. Department of Energy, Office of Basic Energy Sciences - Materials Sciences, under contract No. 
W-31-109-ENG-38 (JDJ, DGH), the National Science Foundation, Office of Science and Technology Centers, under grant No. DMR 91-2000 (OC, DNA, BD), and the U.

S. Department of Energy Distinguished Postdoctoral Research Program (JFM).

1. See, for example, the articles in MRS Bulletin, Vol. 17, No. 8, (August 1992).

2. J.D. Jorgensen; Physics Today, June 1991, p. 34.

3. M.H. Whangbo, D.B. Kang, and C.C. Torardi, Physica C. 158, 371 (1989).

4. Y.J. Uemura, et al., Phys.Rev.Lett. 62, 2317 (1989).

5. J.B. Torrance, Y. Tokura, A.I. Nazzal, A. Bezinge, T.C. Huang, and S.S. Parkin, Phys. Rev. Lett. 61, 1127 (1988).

6. J.L. Tallon, R.G. Buckley, E.M. Haines, M.R. Presland, A. Mawdsley, N.E. Fowler, and J. Loram, Physica C. 185-189, 855 (1991).

7. M.-H. Whangbo and C.C. Torardi, Science. 249, 1143 (1990).

8. J.D. Jorgensen, P. Lightfoot, and S. Pei, Supercond: Sci. Technol. 4, S11 (1991).

9. J.D. Jorgensen, P.G. Radaelli, H. Shaked, J.L. Wagner, B.A. Hunter, J.F. Mitchell, R.L. Hitterman, and D.G. Hinks, J. Supercond. 7, 145 (1994).

10. Y. Tokura, J.B. Torrance, T.C. Huang, and A.I. Nazzal, Phys.Rev.B. .38, 7156 (1988).

11. P.G. Radaelli, D.G. Hinks, A.W. Mitchell, B.A. Hunter, J.L. Wagner, B. Dabrowski, K.G. Vandervoort, H.K. Viswanathan, and J.D. Jorgensen, Phys. Rev. B. 49, 4163 (1994).

12. J.L. Tallon, C. Bernhard, H. Shaked, R.L. Hitterman, and J.D. Jorgensen, Phys. Rev. B. 51, 12911 (1995).

13. Y.J. Uemura, L.P. Le, G.M. Luke, B.J. Stemlieb, W.D. Wu, J.H. Brewer, T.M. Riseman, C.L. Seaman, M.B. Maple, M. Ishikawa, D.G. Hinks, J.D. Jorgensen, G. Saito, and H. Yamochi, Phys. Rev. Lett. 66, 2665 (1991).

14. R.J. Cava, A.W. Hewat, E.A. Hewat, B. Batlogg; M. Marezio, K.M. Rabe; J.J. Krajewski, W.F. Peck Jr., and L.W. Rupp Jr., Physica C. 165, 419 (1990).

15. J.D. Jorgensen, B.W. Veal, A.P. Paulikas, L.J. Nowicki, G.W. Crabtree; H. Claus, and W.K. Kwok, Phys. Rev. B. 41, 1863 (1990).

16. 'J.L. Tallon and N.E. Fowler, Physica C. 204, 237 (1993).

17. Y. Shimakawa, Y. Kubo, T. Manako, and H. Igarashi, Phys. Rev. B. 40, 11400 (1989).

18. Y. Kubo, Y. Shimakawa, T. Manako, and H. Igarashi, Phys.Rev. B. 43, 7875 (1991).

19. H. Shaked, J.D. Jorgensen, B.A. Hunter, R.L. Hitterman, K. Kinoshita, F. Izumi, and T. Kamiyama, Phys. Rev. B. 48, 12941 (1993).

20. Y. Maeno, T. Tomita, M. Kyogoku, S. Awaji, Y. Aoki, K. Hoshino, A. Minami, and T. Fujita, Nature. 328, 512 (1987).

21. J.M. Tarascon, P. Barboux, P.F. Miceli, L.H. Greene, G.W. Hull, M. Eibschutz, and S.A. Sunshine, Phys. Rev. B. 37, 7458 (1988).

22. R.S. Howland, T.H. Geballe, S.S. Laderman, A. Fischer-Colbrie, M. Scott, J.M. Tarascon, and P. Barboux, Phys. Rev. B. 39, 9017 (1989).

23. J.B. Parise, P.L.Gai, M.K. Crawford, in High temperature superconductors: relationship between properties, structure and solid-state chemistry, Edited by J.D. Jorgensen, K. Kitazawa, J.M. Tarascon, M.S. Thompson, and J.B. Torrance, 
(Material Research Society Symposium Proc., Vol. 156, Pittsburgh, PA, 1989) p. 105.

24. R.G. Buckley, D.M. Pooke, J.L. Tallon, M.R. Prestland, N.E. Flower, M.P. Staines, H.L. Johnson, M. Meylan, G.V.M. Williams, and M. Bowden, Physica C. 174, 383 (1991).

25. E.V. Antipov, S.M. Loureiro, C: Chaillout, J.J. Capponi, P. Bordet, J.L. Tholence, S.N. Putilin, and M. Marezio, Physica C. 215, 1 (1993).

26. J.L. Wagner, B.A. Hunter, D.H. Hinks, and J.D. Jorgensen, Phys. Rev. B. 51, 15407 (1995).

27. J.L. Wagner, P.G. Radaelli, D.G. Hinks, J.D. Jorgensen, J.F. Mitchell, , B. Dabrowski, G.S. Knapp, and M.A. Beno, Physica C. 210, 447 (1993).

28. P.G. Radaelli, J.L. Wagner, B.A. Hunter, M.A. Beno, G.S. Knapp, J.D. Jorgensen, and D.G. Hinks, Physica C. 216, 29 (1993).

29. O. Chmaissem, Q. Huang, E.V. Antipov, S.N. Putilin, M. Marezio, S.M. Loureiro, J.J. Cappponi, J.L. Tholence, and A. Santoro, Physica C. 217, 265 (1993).

30. Q. Huang, J.W. Lynn, R.L. Meng, and C.W. Chu, Physica C. 218, 356 (1993).

31. O. Chmaissem, Q. Huang, S.N. Putilin, M. Marezio, and A. Santoro, Physica C. 212,259 (1993).

32. Y. Gao, P. Coppens, D. Cox, and A. Moodenbaugh, Acta Crystallogr..A. 49, 141 (1993).

33. F. Izumi, T. Kondo, Y. Shimakawa, T. Manako, Y. Kubo, H. Igarashi, and H. Asano, Physica C. 185-189, 615 (1991).

34. M.A. Subramanian, J.C. Calabrese, C.C. Torardi, J. Gopalakrishnan, T.R. Askew, R.B. Flippen, K.J. Morrissey, U. Chowdhry, and A.W. Sleight, Nature. 332, 420 (1988).

35. P. Lightfoot, S. Pei, J.D. Jorgensen, Y. Yamada, T. Matsumoto, F. Izumi, and Y. Kodama, Acta Crystallogr. C. 47, 1143 (1991).

36. P. Fischer, J. Karpinski, E. Kaldis, E. Jilek, and S. Rusiedki, Solid State Commun. 69, 531 (1989).

37. R.J. Cava, M. Marezio, J.J. Krajewski,.W.F. Peck Jr., A. Santoro, and F. Beech, Physica C. 157, 272 (1989).

38. H. Takahashi, H. Shaked, B.A. Hunter, P.G. Radaelli, R.L. Hitterman, D.G. Hinks, and J.D. Jorgensen, Phys. Rev. B. 50, 3221 (1994).

39. N. Yamada and M. Ido, Physica C. 203, 240 (1992).

40. .B. Dabrowski, Z. Wang, J.D. Jorgensen, R.L. Hitterman, J.L. Wagner, B.A. Hunter, and D.G. Hinks, Physica C. 217, 455 (1993).

41. B. Dabrowski, Z. Wang, K. Rogacki, J.D. Jorgensen, R.L. Hitterman, J.L. Wagner, B.A. Hunter, P.G. Radaelli, and D.G. Hinks, Phys. Rev. Lett. (in press), (1996).

42. C.W. Chu, L. Gao, F. Chen, Z.J. Huang, R.L. Meng, and Y.Y. Xue, Nature. 365,323 (1993).

43. L. Gao, Y.Y. Xue, F. Chen, Q. Xiong, R.L. Meng, D. Ramirez, C.W. Chu, J.H. Eggert, and H.K. Mao, Phys. Rev. B. 50, 4260 (1994).

44. H. Takahashi, A. Tokiwa-Yamamoto, N. Mori, S. Adachi, H. Yamauchi, and S. Tanaka, Physica C. 218, 1 (1993).

45. A.K. Klehe, J.S. Schilling, J.L. Wagner, and D.G. Hinks, Physica C. 223, 313 (1994). 
46. B.A. Hunter, J.D. Jorgensen, J.L. Wagner, P.G.. Radaelli, D.G. Hinks, H. . Shaked, R.L. Hitterman, and R.B.V. Dreele, Physica C. 221, 1 (1994).

47. D.J. Singh and W.E. Pickett, Phsyica C. 233, 237 (1994).

48. D.L. Novikov, O.N. Myrasov, and A.J. Freeman, Physica C. 222, 38 (1994).

49. D.L. Novikov and AJ. Freeman, Physica C. 216, 273 (1993).

50. D.L. Novikov and AJ. Freeman, Physica C. 212, 233 (1993).

51. R.S. Markiewicz, Physica C. 217, 381 (1993).

52. D.M. Newns, C.C. Tsuei, P.C. Pattnaik, and C.L. Kane, Comm. Condens. Matt. Phys. 15, 273 (1992).

53. D.J. Singh, Phys. Rev. B. 48, 3571 (1993).

54. E.V. Antipov, J.J. Capponi, C. Chaillout, O. Chmaissem, S.M. Loureiro, M. Marezio, S.N. Putilin, A. Santoro, and J.L. Tholence, Physica C. 218, 348 (1993).

55. M. Cantoni, A. Schilling, H.-U. Nissen, and H.R. Ott, Physica C. 215, 11 (1993).

56. S.M. Loureiro, E.V. Antipov, J.L. Tholence, J.J. Capponi, O. Chmaissem, Q. Huang, and M. Marezio, Physica C. 217, 253 (1993).

57. S.N. Putilin, E.V. Antipov, and M. Marezio, Physica C. 212, 266 (1993).

58. D.J. Singh and W.E. Pickett, Phys. Rev. Lett. 73, 476 (1994):

59. M. Itoh; A. Tokiwa-Yamamoto, S. Adachi, and H. Yamauchi, Physica C. 212, 271 (1993).

60. S. Adachi, A. Tokiwa-Yamamoto, M. Itoh, K. Isawa, and H. Yamauchi, Physica C. 214, 313 (1993).

61. A. Umezawa, W. Zhang, A. Gurevich, Y. Feng, E.E. Hellstrom, and D.C. Larbalestier, Nature. 364, 129 (1993).

62. U. Welp, G.W. Crabtree, J.L. Wagner, D.G. Hinks, P.G. Radaelli, J.D. Jorgensen, J.F. Mitchell, and B. Dabrowski, Appl. Phys. Lett. 63, 693 (1993).

63. U. Welp, G.W. Crabtree; J.L. Wagner, and D.G. Hinks, Physica C. 218, 373 (1993).

64. J.A. Lewis, C.A. Platt, M. Weigmann, M. Teepe, J.L. Wagner, and D.H. Hinks, Phys. Rev. B. 48, 7739 (1993).

65. J. Shimoyama, S. Hahakura, R. Kobayashi, K. Kitazawa, K. Yamafuji, and K. Kishio, Physica C. 235-240, 2795 (1994).

66. J. Shimoyama, S. Hahakura, K. Kitazawa, Y. Yamafuji, and K. Kishio, Physica C. 224, 1 (1994).

67. J. Shimoyama, K. Kishio, S. Hahakura, K. Kitazawa, K. Yamaura, Z. Hiroi, and M. Takano, in Advances in Superconductivity VII, Proc. of the 7th International Symposium on Superconductivity (ISS'94), (Edited by K. Yamafuji and T. Morishita), Vol. p. 287. Springer-Verlag, Tokyo (1995).

68. K. Yamaura, J. Shimoyama, S. Hahakura, Z. Hiroi, M. Takano, and K. Kishio, Physica C. 246, 351 (1995).

69. K.E. Gray and D.H. Kim, Physica C. 180, 139 (1991).

70. K.E. Gray, Appl. Superconductivity. 2, 295 (1994).

71. O. Chmaissem, D.N. Argyriou, D.G. Hinks, J.D. Jorgensen, B.G. Storey, H. Zhang, L.D. Marks, Y.Y. Wang, V.P. Dravid, and B. Dabrowski, Phys. Rev. $B$. 52, 15636 (1995).

72. O. Chmaissem, J.D. Jorgensen, K. Yamaura, Z. Hiroi, M. Takano, J. Shimoyama, and K. Kishio, Phys. Rev. B. (in press) (1996). 